\title{
REVISION TOTAL HIP REPLACEMENT USING LONG CURVED FULLY HYDROXYAPATITE-COATED MODULAR STEMS WITH DISTAL INTERLOCKING
}

\author{
Kalin Mihov',2, Maxim Zagorov,2, Svetoslav Dobrilov',2, Atanas Tabakov ${ }^{2}$, \\ Georgi Zhelyazkov ${ }^{2}$ \\ ${ }^{1}$ Department of Orthopedics and Traumatology, Faculty of Medicine, \\ Medical University of Varna \\ ${ }^{2}$ Department of Orthopedics and Traumatology, St. Marina University Hospital, Varna
}

\begin{abstract}
Successful femoral reconstruction in revision total hip replacement needs to address variable metadiaphyseal bone defects and still represents a controversial issue. We present our clinical experience with the use of two types of long revision, curved, fully hydroxyapatite (HA)-coated titanium femoral stems with distal interlocking. A group of 20 patients has been followed up clinically and radiographically for a period of $\mathbf{1 2 . 1}$ months (3-30 months). Indications included aseptic and septic loosening as well as adverse local tissue reactions (ALTR) to metal debris. The major complications in our series included postoperative instability and intraoperative periprosthetic femoral fracture. Revision curved modular fully HA-coated stems with distal interlocking provide for good primary stem stability and successful secondary osteointegration in revision total hip arthroplasty (THA) for both aseptic and septic loosening in the setting of femoral bone defects. Longer follow-up in a larger cohort of patients is needed to confirm the good and very good short-term results and assess femoral bone remodeling. Scr Sci Med. 2018;50(1):20-24
\end{abstract}

Keywords: total hip replacement, revision, HA stems

\section{INTRODUCTION}

Revision hip arthroplasty is a challenging procedure due to many potential complications. Successful femoral reconstruction of different bone defects in the metadiaphyseal zone is a current issue in the present revision hip arthroplasty. Loosening of the primary femoral component leads to femoral canal widening and cortical metaphyseal bone sclerosis. This leads to poor contact with the bone ce-

Address for correspondence:

Kalin Mihov

Department of Orthopedics and Traumatology

St. Marina University Hospital

1 Hr. Smirnenski Blvd

9000 Varna

e-mail:kalinmihov@mail.bg

Received: November 14, 2017

Accepted: March 16, 2018 ment, which explains the poor revision results using cemented stems (1-5)

Cementless stems are a preferred option in revision hip arthroplasty for many surgeons. The basic principle when using such implants is achieving primary mechanical stability in healthy bone, leading to secondary osteointegration and biological fixation. Other challenges of cementless revision are reconstruction of preoperative and iatrogenic bone defects, restoring hip biomechanics and physiological bone loading $(6,7)$.

There are several variants of cementless femoral stems: femoral stems with metadiaphyseal fixation, cylindrical straight stems with fully porous coverage; distally fluted, conical stems (monobloc or modular) and fully HA-coated stems with distal locking. In terms of reliability, insertion and possibility for combination with trans-trochanteric osteotomy, cement- 
Kalin Mihov, Maxim Zagorov, Svetoslav Dobrilov et al.

less HA stems have no equivalent (8-11). Curved titanium fully HA-coated stems with distal locking have substantial primary axial and rotational stability (20), and rapid osteointegration due to extensive HA coating. The stem design allows the restoration of hip biomechanics, remodeling of the metadiaphyseal defects and reduces the need of osteoplasty (12-14)

\section{MATERIALS AND METHODS}

For the period October, 2013 - November, 2017 28 patients ( 29 hips) were operated on. The mean age of the patients was 67.5 (37-79). The male:female ratio was 12:16 with a mean follow-up of 12.1 months (3-30). In $2 / 3$ of the patients total hip revision arthroplasty was performed. Eighteen cases were with aseptic loosening and 7 with septic. Two patients were with periprostetic fracture after trauma and one with adverse reaction to metal debris.

In the majority of the cases we used Atlantis (Symbios, Yverdon les Bains, Switzerland) - Ti (6Al4V) - anatomical modular stem, fully HA-coated with an option for distal locking. This stem permits either endofemoral or transfemoral insertion. In 5 patients the implant of choice was REEF (Depuy, Johnson\&Johnson) with curved modular stem, fully HA-coated with distal locking and primary transfemoral insertion (Fig.1).
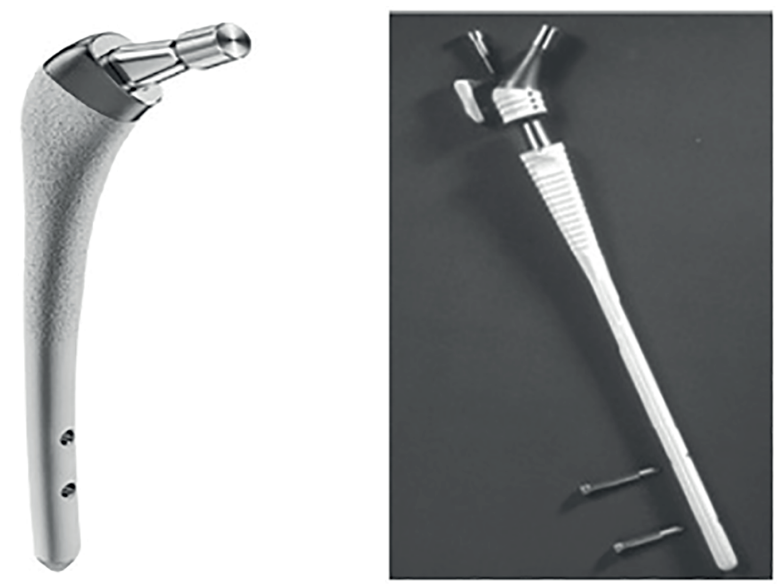

Fig. 1. Curved titanium stems with full HA coating Atlantis (left) and REEF (right)

We have used a standard extensive posterolateral surgical approach and in only one case - an enlarged lateral approach. Extraction of the primary implant in $1 / 3$ of the cases was done via distal cor- tical osteotomy and in 9 patients - via transfemoral approach. Distal locking of the revision implant for additional stability was required in eight of the revisions and in two osteoplasty was performed due extensive bone loss.

The postoperative Harris Hip Score (HHS) was 81.2 pts. (72-93) and only one patient had distal tight pain with no data of loosening of the revision implant. X-ray data for bone ingrowth over the stem was reported in $55 \%$ of the cases and this percentage is due to different follow-up periods (Fig.2). All of the patients had bone restoration of the osteotomized section of the femur and stable distal fixation (Fig.3). There is no evidence for stem subsidence and we noticed proximal stress shielding in only 3 cases.

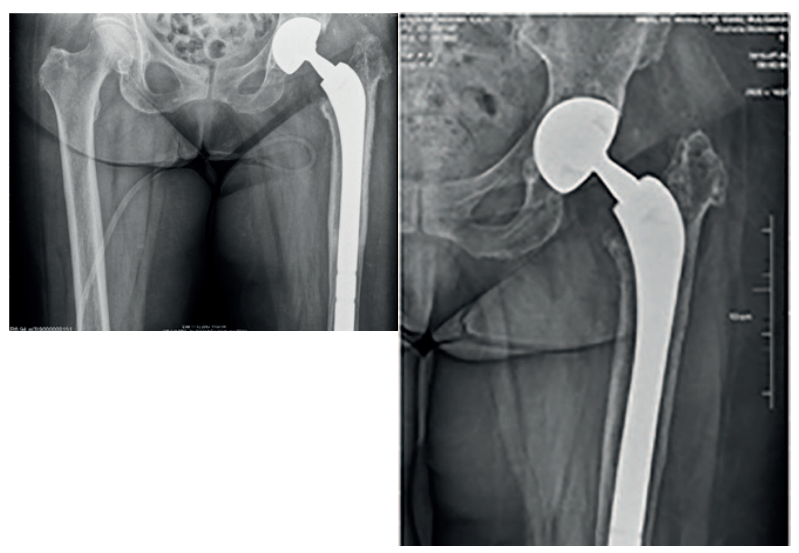

Fig. 2. X-ray images: postoperatively (left) and 8 months postoperatively (right)

In three patients we had early postoperative dislocation, which was revised with different implants and one was treated with close reduction. We had one iatrogenic periprosthetic fracture and one pseudoarthrosis of the greater trochanter. We observed no complications from the distal locking. In $15 \%$ there was heterotopic ossification with no clinical significance.

\section{DISCUSSION}

The use of revision femoral stems has increased progressively due to the already prevalent primary hip arthroplasty, higher survival of patients with hip arthroplasty and its use in younger patients. Revision arthroplasty is a challenge for a number of reasons, such as femoral/acetabular bone deficiency, age, etc. 

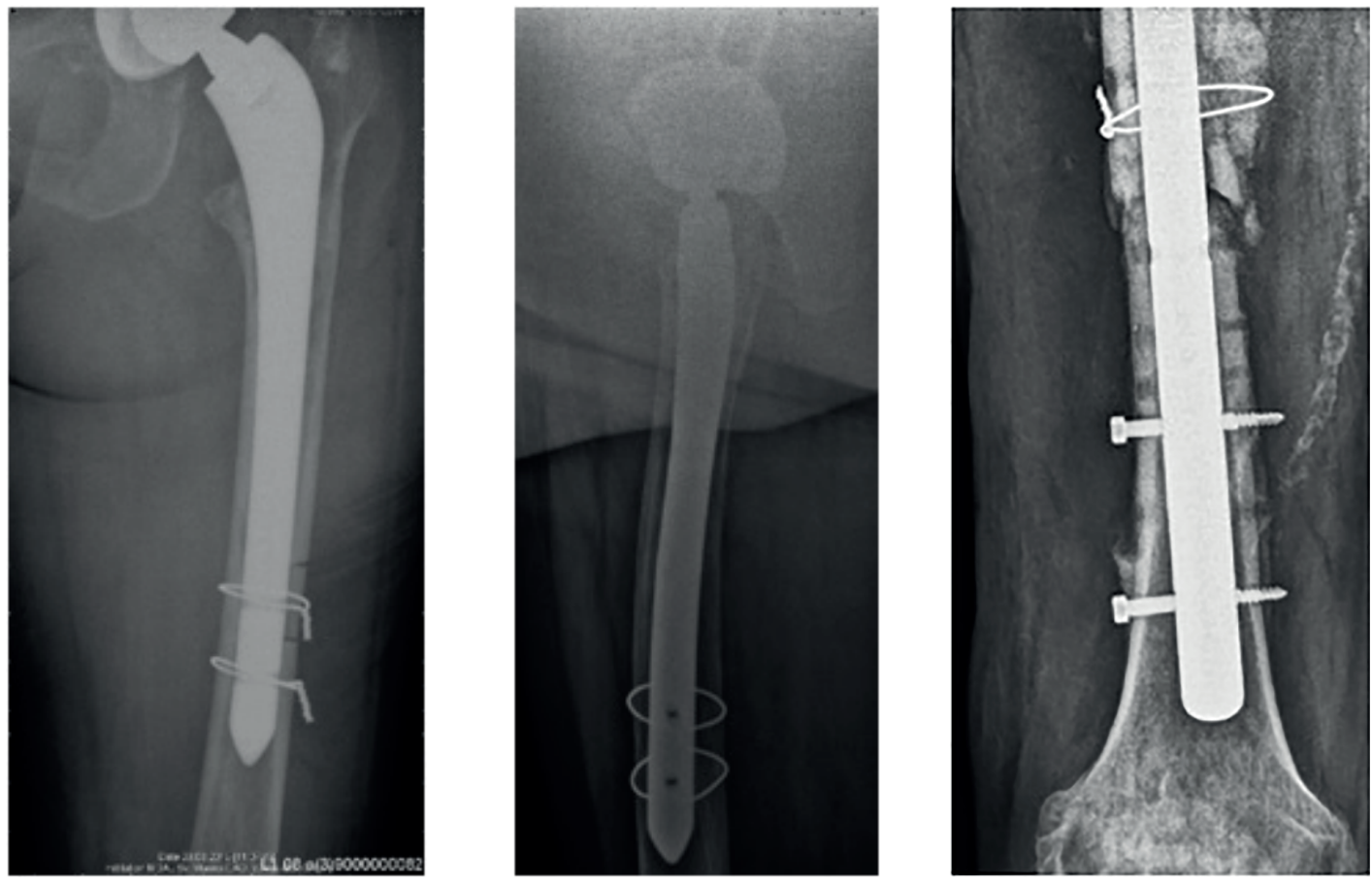

Fig. 3. Healed osteotomized section of the femur and stable distal fixation

The revision in the sense of proximal femoral bone deficiency or periprosthetic fracture remains an unresolved problem. There are very few midterm and long-term results of the use of fully HAcoated stems in the revision prosthesis compared to the excellent results in primary arthroplasty. Given the bone loss and/or bone bioinsufficiency present in most revisions, proximally covered stems are not recommended in revision arthroplasty, given the primary stability of the revision implant $(12,15-17)$

Distal locking contributes both to the preservation of the limb length and to the axial and rotational stability of the stem, and reduces the need for osteoplasty in bone deficiency, especially around the femoral calcar (2, 18-20). Mahomed reported an increase in torsional stability by $320 \%$ and in axial by $230 \%$ using a distal lock (10) By itself, however, locking is not a method of stabilizing the stem. It has only a complementary effect. This is also confirmed by Storeanos in the passage of the effect of filling the femoral canal from the stem (20).

Stability is dependent on the distal filling of the femoral canal, and locking is indicated in cases of inability to achieve a circumferential press-fit or a three-point contact (21). Long conical stems with dis- tal fixation are a variant of massive femoral defects (Paprosky type 2 and 3) - a modularity, which allows for restoration of the length of the limb, correction in the offset and cervical version, as well as implantation with extended trochanter osteotomy $(9,13)$. The curved anatomical stems with extensive HA coating provide excellent stability osteointegration and reliable long-term outcomes (22). The level of cortical femorotomy is also important - it is necessary to be at a distance of one femoral width above the first locking hole (4).

Recent comparative analyses in straight partial HA-coated, curved, fully coated and curved partially coated revision stems show significantly worse results in the first group compared to the other two. Regarding the functional score and osteointegration of the stems, the second group shows superiority over the rest. Curved stems (second and third group) lead to significantly fewer cases of low thigh pain $(4,23)$. The coated stems have significantly lower stress shielding compared to porous stems (18). The hydroxyapatite coating has an osteoinductive effect in contact with vital bone (3) and this is also the reason for the low incidence of hip pain after revision with fully HA-coated stems. The occurrence of such pain after implanted cementless stems is due to the 
Kalin Mihov, Maxim Zagorov, Svetoslav Dobrilov et al.

micromotion of the stem and/or increased stress on the thigh. In addition to osteointegration, an important moment is also the dense press-fit of the stem, which further reduces the risk of thigh pain $(8,24)$. Currently, we have observed no revision due to aseptic loosening and we believe that once induced, the implant integration is permanent .

The stems have $97.7 \%$ 5-year survival and 2\% dislocations in 43 total hip revisions with a distal locked stem; $0 \%$ subsidence, $80 \%$ bone adhesion, HHS of 75 pts. in 15 patients with insufficient femoral isthmus and a curved stent with distal locking. There is evidence of 5-year survival using fully HAcoated curved femoral stems with distal locking in patients with isthmical bone loss $(25,26)$.

\section{CONCLUSION}

Revision THA is challenge, especially in cases with massive bone loss. The increasing number of primary THA will lead to an increase of the revision cases too. Fully HA-coated stems in combination with distal locking are an excellent option, giving primary stability, even in cases with extensive bone defects. Rapid osteointegration of the implant and bone remodeling reduce the risk of complications related to the stability. Our short-term experience with these implants is promising, especially in patients with massive bone loss, deformities or those with septic loosening. Primary axial and rotational stability combined with distal locking and the osteoinductive effect of the HA stem are without analog.

\section{REFERENCES}

1. Mulroy WF, Harris WH. Revision total hip arthroplasty with use of so-called second generation cementing techniques for aseptic loosening of the femoral component. J Bone Joint Surg Am. 1996; 78(3):325-30.

2. Engh CA, Culpepper WJ II, Kassapidis E. Revision of loose cementless femoral prostheses to larger porous coated components. Clin Orthop Relat Res. 1998;(347):168-78.

3. Geesink RGT, De Groot K, Klein CP. Bonding of bone to apatite-coated implants. J Bone Joint Surg Br. 1988;70(1):17-22.

4. Mertl P, Philippot R, Rosset P, Migaud H, Tabutin J, Van de Velde D. Distal locking stem for revision femoral loosening and peri-prosthetic frac- tures. Int Orthop. 2011;35(2):275-82. doi: 10.1007/ s00264-010-1182-6.

5. Katz RP, Callaghan JJ, Sullivan PM, Johnston RC. Results of cemented femoral revision total hip arthroplasty using improved cementing techniques. Clin Orthop Relat Res. 1995;(319):178-83.

6. Singh S, Trikha SP, Edge AJ. Hydroxyapatite ceramic coated femoral stems in young patients: a prospective ten-year study. J Bone Joint Surg Br. 2004;86(8):1118-23.

7. Whiteside LA. The effect of stem fit on bone hypertrophy and pain relief in cementless total hip arthroplasty. Clin Orthop Relat Res. 1989;(247):138-47.

8. Engh CA, Bobyn JD, Glassman AH. Porous-coated hip replacement: the factors governing bone ingrowth, stress shielding and clinical results. J Bone Joint Surg Br. 1987;69(1):45-55.

9. Kinov P, Antonov B, Tanchev P, Tsvetanov L, Georgiev G, Tivchev P. Revision of femoral component with modular conical stem by means of distal fixation. Bul J Ortop Trauma. 2017;1:21-5.

10. Mahomed N, Schatzker J, Hearn T. Biomechanical analysis of a distally interlocked pressfit femoral total hip prosthesis. J Arthroplasty. 1993;8(2):129-32.

11. Moreland JR, Bernstein ML. Femoral revision hip arthroplasty with uncemented, porous-coated stems. Clin Orthop Relat Res. 1995;(319):141-50.

12. Capello WN, D’Antonio JA, Manley MT, Feinberg JR. Hydroxyapatite in total hip arthroplasty: clinical results and critical issues.Clin Orthop. 1998;355:200-11.

13. Kinov P, Tivchev P. Revision Hip Arthroplasty: Management of Bone Loss Arthroplasty-Update. 2013. Available from: - intechopen.com. doi: $10.5772 / 53249$.

14. McNally S, Shepperd JA, Mann CV, Walczak JP. The results at nine to twelve years of the use of a hydroxyapatite-coated femoral stem. J Bone Joint Surg Br. 2000;82(3):378-82.

15. Cameron HU.The long term success of modular proximal fixation stems in revision total hip arthroplasty. J Arthroplasty. 2002;17(4 Suppl 1):138-41.

16. Rubash HE, Harris WH. Revision of nonseptic, loose, cemented femoral compo- 
nents using modem cementing techniques. J

Arthroplasty.1988;3(3):241-8.

17. Skinner JA, Kroon PO, Todo S, Scott G. A femoral component with proximal HA coating: an analysis of survival and fixation at up to ten years. J Bone Joint Surg Br. 2003;85(3):366-70.

18. Moreland JR, Moreno MA (2001) Cementless femoral revision arthroplasty of the hip: minimum 5 years follow up. Clin Orthop Relat Res. 2001;(393):194-201.

19. Paprosky WG, Greidanus NV, Antoniou J (1999) Minimum 10- year results of extensively porouscoated stems in revision hip arthroplasty. Clin Orthop Relat Res. 1999;(369):230-42.

20. Sotereanos N, Sweschke J, Raukear GJ, DeMeo PJ, Bargiotas K, Wohlrab D. Revision total hip arthroplasty with a custom cementless stem with distal cross-locking screws. Early results in femora with large proximal segmental deficiencies. J Bone Joint Surg Am. 2006;88(5):1079-84.

21. Mousa Y, Ganzoury I, Noaman M. Role of Distal Locking Screws in Stability of Modular Cementless Revision Total Hip Replacement. Res J Med Med Sci. 2009;4(2): 469-74.

22. May O, Soenen M, Laffargue P, Girard J, Migaud H. Distally locked stems for revision hip arthroplasties with severe femoral bone loss. Results of 101 cases after a mean follow-up of 6 years. Orthopaedic Proceedings.2010;92-B(Suppl 2):305-6.

23. Estok DM, Harris WH. Long term results of cemented femoral revision surgery using secondgeneration techniques. An average 11.7-year follow-up evaluation. Clin Orthop Relat Res. 1994;(299):190-202.

24. Weeden SH, Paprosky WG. Minimal 11-year follow-up of extensively porouscoated stems in femoral revision total hip arthroplasty. J Arthroplasty. 2002;17(4 Suppl 1):134-7.

25. Fink B, Grossmann A, Fuerst MS. Distal interlocking screws with a modular revision stem for revision total hip arthroplasty in severe bone defect. J Arthroplasty. 2010;25(5):759-65. doi: 10.1016/j. arth.2009.05.019.

26. Philippot $\mathrm{R}$ et al. Femoral deficiency reconstruction using a hydroxyapatite-coated locked modular stem. A series of 43 total hip revisions. Orthop Traumatol Surg Res. 2009;95(2):119-26. doi: 10.1016/j.otsr.2008.09.009. 